\title{
Boron toxicity effects on grafted and non-grafted pepper (Capsicum annuum) plants
}

\author{
Eleana Sarafi ${ }^{1 *}$, Anastasios Siomos ${ }^{1}$, Pavlos Tsouvaltzis $^{1}$, Christos Chatzissavvidis ${ }^{2}$, Ioannis \\ Therios $^{1}$
}

${ }^{1}$ Department of Horticulture, Aristotle University, 54124 Thessaloniki, Greece. ${ }^{2}$ Department of Agricultural Development, Democritus University of Thrace, 68200 Orestiada, Greece.

*Corresponding author: esarafi@agro.auth.gr

\begin{abstract}
Grafting is a vegetative plant propagation technique. In a grafted plant, the upward supply of water and mineral nutrients as well as the downward flow of photosynthesis are modified. In this context, the objectives of this work were to find out whether the grafting of pepper plants (Capsicum annuum L. family Solanaceae) reduces leaf boron concentration of some commercial cultivars under boron toxicity and to examine the effects of grafting and scion-cultivars on the levels of phenols, flavonoids and antioxidant capacity. Ungrafted plants of the cultivars Century, Twingo, Imperial and Arlequin, as well as grafted Twingo, Imperial and Arlequin plants as scions, and Century as rootstock were used. The plants were treated with $5 \mathrm{mg} \mathrm{L}^{-1}$ boron for 7, 14, 21 and 28 days. After 21 and 28 days of treatment, grafting significantly reduced the boron concentration in the leaves of the scion-cultivars while it was increased by $80 \%$ in the non-grafted plants. After 21 days of boron treatment, it was found that grafting reduced the concentration of leaf phenol to $60-70 \%$ in ungrafted Century plants. In Century $x$ Twingo there was a 33\% increase in the flavonoid concentration of leaves after 7 days grafting; while in the Century $x$ Imperial and Century x Arlequin combinations this was decreased by $75-92 \%$ compared to non-grafted Century plants. The antioxidant capacity of leaves after 21 days treatment increased in all rootstockscion combinations by $28 \%$ as measured by the FRAP and DPPH methods. In conclusion, grafting reduced boron concentration in the leaves of the tested scion-cultivars, as well as having an effect on the phenol and flavonoid concentrations and antioxidant capacity of the leaves.
\end{abstract}

Keywords: Antioxidant capacity, boron, flavonoids, grafting, phenol 


\section{Introduction}

Boron (B) toxicity is a serious agricultural problem which limits productivity in various areas of the world. This problem occurs in B rich soils or in soils exposed to $\mathrm{B}$ rich irrigation water, sewage sludge, or fly ash (Chatzissavvidis and Therios, 2011). In the near future, there could be an intensification of B toxicity in the Mediterranean and other areas as a consequence of inadequate precipitation. Due to the limited supply and high market demand for vegetables globally, pepper (Capsicum annuum L. family Solanaceae) plants are frequently cultivated in marginal soil conditions, such as low soil P (Tanwar et al., 2013) and high B. Grafting cultivars (cvs) onto rootstocks capable of reducing the effect of external stresses, such as high manganese (Mn) levels (Savvas et al., 2009), salts (He et al., 2009), as well as B (Chatzissavvidis and Therios, 2011), gives the rootstock the ability to alleviate these adverse effects. Furthermore, Edelstein et al. (2011) indicated that pumpkins roots excluded $74 \%$ of available sodium (Na) when pumpkin was used as a rootstock. Grafting experiments on olives (Chatzissavvidis et al., 2008) and almond on Nemared peach (El-Motaium et al., 1994) demonstrated the ability of the rootstock to influence B accumulation in leaves as well as scion survival.

B toxicity reduces growth and causes chlorosis starting at the leaf tip and the margin of mature leaves (Paparnakis et al., 2013, Sarafi et al., 2016). A number of physiological processes have been shown to be altered by B toxicity. This includes membrane damage, disruption of cell wall development, metabolic disruption by binding to the moieties of adenosine triphosphate (ATP), nicotinamide adenine dinucleotide (NADH) and nicotinamide adenine dinucleotide phosphate (NADPH), and inhibition of cell division and elongation (Reid et al., 2004). In addition, plants suffering from B toxicity also exhibit increases in antioxidant capacity (Cervilla et al., 2007), as well as in phenolic metabolism (Ardic et al., 2009). Peppers contain moderate to high levels of phenolics or flavonoids, phytochemicals that are important antioxidant components of a plant-based diet which may reduce the risk of degenerative diseases (Hasler, 1998). Furthermore, B application significantly increased dry fruit yield in Capsicum annuum L. and that maximum yield was associated with the internal B requirement (Rafique et al., 2012). Boron toxicity caused leaf chlorosis and decreased fresh and dry yield, fruit number and plant height (Akinci, 2006).

Grafting is widely used for various vegetable crops having the potential to greatly reduce costs. The use of grafted vegetable seedlings is popular in many countries (e.g. Savvas et al., 2009; Schwarz et al., 2010). In recent years, the cultivated areas of grafted Solanaceae, including peppers, have increased in order to improve resistance to soil borne diseases, as well as tolerance to abiotic stresses, such as B toxicity (Schwarz et al., 2010). For example, there was a lower accumulation of B in leaves in melon plants when they were grafted onto Cucurbita (TZ-148), highlighting the ability of the rootstock to exclude B and limit its transportation to the leaves (Edelstein et al., 2005). Additionally, Edelstein et al. (2005) found that the fruit yield of the grafted plants was less affected by $B$ accumulation in the leaves than in the non-grafted plants, however not offering any explanation for this phenomenon. Grafting was also found to improve salinity tolerance of the tomato plant by limiting the transportation of sodium $(\mathrm{Na})$ and chloride $(\mathrm{Cl})$ to the shoot (Estan et al., 2005).

As B toxicity is a serious problem in agricultural lands, we assumed that grafting may reduce B concentration in C. annuum L. (family Solanaceae) plants by using the commercial cultivar (cv) Century (C) as 
a model rootstock. Therefore, the objectives of the current study were to evaluate the time course of B accumulation in non-grafted pepper plants of the cvs C, Twingo (T), Imperial (I) and Arlequin (A) and the grafted plants of the cultivar T, A and I on $\mathrm{C}$ as rootstock after irrigation with a solution containing $5 \mathrm{mg}$ $\mathrm{B} \mathrm{L}^{-1}$. In addition, another objective was to evaluate the effects of grafting and scion-cultivars on the time course of the phenol and flavonoid concentration of the leaves, as well as the antioxidant capacity.

\section{Materials and Methods}

\subsection{Plant material and growth conditions}

A greenhouse experiment was conducted in a heated greenhouse at the farm of the Aristotle University of Thessaloniki, Greece (latitude $40^{\circ} 53^{\prime} \mathrm{N}$, longitude $22^{\circ} 99^{\prime}$ E) from January to February of 2014. Pepper (Capsicum annuum L.) grafted and non-grafted plants (non-grafted plants of C, T, I and A and grafted plants with the cvs T, A and I on C, as rootstock) were grown for 30 days in plastic disks (120 plants per disk) filled with a peat-vermiculite mixture. Following, the experimental plants, at the fourth true leaf stage of growth were transplanted in plastic pots $3 \mathrm{~L}$ (18 $\mathrm{cm}$ upper diameter, $12 \mathrm{~cm}$ lower diameter and $17 \mathrm{~cm}$ in height) that were filled with perlite and placed on benches in the experimental greenhouse. The conditions in the greenhouse were: relative humidity $(\mathrm{RH})$ at $60-70 \%$, temperature between $20-25^{\circ} \mathrm{C}$, and the photosynthetic photon flux density (PPFD) of 900 $\mu$ mole $\mathrm{m}^{-2} \mathrm{~s}^{-1}$ which was measured at the top of the plants with a quantum sensor.

The experimental plants were irrigated with 50\% Hoagland nutrient solution in macronutrients and full strength in micronutrients modified to include $5 \mathrm{mg}$ $\mathrm{L}^{-1} \mathrm{~B}$ (B toxicity). The concentration of $0.2 \mathrm{mg} \mathrm{B} \mathrm{L}^{-1}$ (adequate level) in the solution is not included since the aim of our study was to study the effect of B toxicity. Furthermore, our preliminary data did not indicate any significant differences among the $\mathrm{C}$ as rootstock and the grafting combinations $\mathrm{CxT}, \mathrm{CxI}$ and $\mathrm{CxA}$ in respect to leaf $\mathrm{B}$ concentration, phenols, flavonoids, and antioxidant capacity. Each treatment consisted of five pots containing 20 plants (4 plants per pot) which were irrigated every second day with $300 \mathrm{ml}$ nutrient solution per pot. To avoid accumulation of B or salts in the substrate each pot was leached out with $300 \mathrm{ml}$ of distilled water at the end of each week (w). The nutrient solution ( $\mathrm{pH}$ 5.5-6.0) contained the following chemicals: $3 \mathrm{mM}$ potassium nitrate $\left(\mathrm{KNO}_{3}\right), 2 \mathrm{mM}$ calcium nitrate tetrahydrate $\left(\mathrm{Ca}\left(\mathrm{NO}_{3}\right) 24 \mathrm{H}_{2} \mathrm{O}\right), 1 \mathrm{mM}$ ammonium dihydrogen phosphate $\left(\mathrm{NH}_{4} \mathrm{H}_{2} \mathrm{PO}_{4}\right), 0.5 \mathrm{mM}$ magnesium sulfate heptahydrate $\left(\mathrm{MgSO}_{4} 7 \mathrm{H}_{2} \mathrm{O}\right)$, full strength micronutrients: $50 \mu \mathrm{M}$ potassium chloride $(\mathrm{KCl}), 5 \mathrm{mg} \mathrm{L}^{-1}$ $\mathrm{B}$ as boric acid $\left(\mathrm{H}_{3} \mathrm{BO}_{3}\right), 2 \mu \mathrm{M}$ manganese sulfate monohydrate $\left(\mathrm{MnSO}_{4} \mathrm{H}_{2} \mathrm{O}\right), 2 \mu \mathrm{M}$ zinc sulfate heptahydrate $\left(\mathrm{ZnSO}_{4} 7 \mathrm{H}_{2} \mathrm{O}\right), 0.5 \mu \mathrm{M}$ copper sulfate pentahydrate $\left(\mathrm{CuSO}_{4} 5 \mathrm{H}_{2} \mathrm{O}\right), 0.5 \mu \mathrm{M}$ molybdic acid $\left(\mathrm{H}_{2} \mathrm{MoO}_{4}\right), 85 \%$ molybdenum trioxide $\left(\mathrm{MoO}_{3}\right)$, and $20 \mu \mathrm{M}$ ethylenediamine di-2-hydroxyphenyl acetate (Fe.EDDHA).

At the end of the $1^{\text {st }}, 2^{\text {nd }}, 3^{\text {rd }}$ and $4^{\text {th }}$ weeks, one plant per pot was removed ( 5 plants per treatment), separated into roots and tops; while all the fully expanded leaves of each plant below the $3^{\text {rd }}$ leaf from the top in each replicate, which most clearly reflect the nutritional and metabolic status caused by B toxicity, were used to determine: B concentration, total phenols, and total flavonoids, as well as the antioxidant capacity expressed as Ferric reducing antioxidant potential (FRAP) and 2,2-diphenyl-1-picryl hydrazyl (DPPH) (\% inhibition and $\mathrm{mM}$ ascorbic acid $\mathrm{g}^{-1}$ F.W.). B determination was made in the leaves of ungrafted T, A and I, as well as in the leaves and roots of Century, CxT, CxA, and CxI plants. 
The experiment lasted for $28 \mathrm{~d}$ when visible B toxicity symptoms appeared in the plants exposed to $5 \mathrm{mg}$ $\mathrm{L}^{-1} \mathrm{~B}$ treatment (e.g. older leaves displayed chlorosis and brown necrotic spots or drying of leaf tissue at the tips and edges), whereas B toxicity symptoms did not appear in the leaves of plants treated with the same treatment at 7 to $21 \mathrm{~d}$. Leaf drying and chlorosis often progressed towards the center between the veins, as more and more B accumulated.

\subsection{Plant sampling}

After plant removal at 7, 14, 21 and $28 \mathrm{~d}$ from the initiation of the experiment, ungrafted C, T, I and A, and grafted combinations of CxT, CxI and CxA plants were separated into leaves and roots. The plant material was rinsed once in tap and twice in distilled water, then blotted dry on filter paper. At each sampling, leaf matter was used fresh for the analysis of total phenols, total flavonoids, FRAP, and DPPH. The rest of the leaf and all of the root material were used for another sample which was dried in a forced-air oven at $68^{\circ} \mathrm{C}$ for 48 hours, ground in a Willey mill to pass through a 30 -mesh screen which was then used for B analysis.

\subsection{Boron determination}

Tissue B determination was made for the whole leaf mass per plant according to Azomethine- $\mathrm{H}$ method (Bingham, 1982).

\subsection{Total phenols}

Tissue phenol determination of plant samples was made according to a method using the Folin-Ciocalteau reagent as described by Sarafi et al. (2017), and expressed as mg gallic acid equivalent (GAE) $\mathrm{g}^{-1}$ of fresh weight (FW).

\subsection{Total flavonoids}

Tissue flavonoid determination of plant samples was made according to a colorimetric method as described by Sarafi et al. (2017). Rutin was used as the standard compound for the quantification of total flavonoids. Values were expressed as $\mathrm{mg}$ of rutin $\mathrm{g}^{-1} \mathrm{FW}$.

\subsection{Antioxidant capacity}

To estimate the antioxidant capacity, two methods were used: Ferric reducing antioxidant potential (FRAP) and 2,2-diphenyl-1-picryl hydrazyl (DPPH) as described by Sarafi et al. (2017). The FRAP assay establishes antioxidant capacity as reductants: a redox-linked colorimetric reaction of the reduction of the $\mathrm{Fe}^{3+}$ 2,4,6-tripyridyl-s-triazine to a blue-colored $\mathrm{Fe}^{2+}$ complex at low $\mathrm{pH}$ is measured spectrophotometrically at $593 \mathrm{~nm}$. The extracts were incubated at room temperature and after one $\mathrm{h}$, the FRAP reagent and the absorbance were recorded. The reducing power is expressed as $\mu \mathrm{mol}$ ferrous sulfate $\left(\mathrm{FeSO}_{4}\right) \cdot \mathrm{g}^{-1}$.

The DPPH method measures the radical scavenging activity of antioxidants against free radicals, as is DPPH. Their activity was calculated based on the percentage of scavenged DPPH as follows: Scavenging activity $(\%)=[1-($ Absorbance of sample at $517 \mathrm{~nm} /$ Absorbance of control at $517 \mathrm{~nm}$ )] x 100. The DPPH method is not specific to any particular antioxidant component, but applies to the overall antioxidant capacity of the sample. Among other methodologies tested, the DPPH method seemed to be the most accurate (Meriño-Gergichevich et al., 2015).

\subsection{Data analysis}

The experimental layout was a completely randomized design with 4-rooted cultivars and 3 scion-rootstock combinations, five replicates per treatment with 
measurements taken 4 times. The data were subjected to analysis of variance (ANOVA) using the statistical package SPSS 17.0 (SPSS Inc. Chicago, Illinois, USA). Data were checked for normality and homogeneity of variances. No important deviations were observed. To compare the means, the Duncan's multiple range test was used at $p \leq 0.05$ to establish significant differences among the treatments. We used Duncan's multiple test because this is a multiple range test comparison of means procedure, especially protective against (Type I) inflation error and it is commonly used in agricultural research (e.g. Mastrogiannidou et al., 2016). For calculation of regression equations, the statistical package SPSS 17.0 was used. Correlation quantified the degree to which the dependent variable (B) and the independent variable (time) are related.

\section{Results}

\subsection{Boron}

B concentrations of leaves in the grafted and nongrafted plants are presented as a function of grafting treatments in 4 exposure times (Figures 1A, 1B, 1C, 1D, Figures 2A, 2B, 2C, 2D). For both non-grafted and grafted pepper plants, $\mathrm{B}$ concentration in leaves was mostly related to the amount of exposure time to high B containing solution. Furthermore, the cv exerted a significant effect on leaf $\mathrm{B}$ concentration. In this sense, on the $21^{\text {st }}$ (Figure 1C) and $28^{\text {th }} \mathrm{d}$ (Figure 1D), the non-grafted $\mathrm{C}$ plants registered the highest foliar concentration of B. In the first $7 \mathrm{~d}$ of B treatment, the non-grafted $\mathrm{C}$ plants had a $\mathrm{B}$ concentration about 50 $\mu \mathrm{g} \mathrm{g}^{-1}$ dry weight (DW), while the combination CxT had significantly lower B concentration. The leaf B concentrations of $\mathrm{CxI}$ and $\mathrm{CxA}$ combinations were 64 and $107 \mu \mathrm{g} \mathrm{g}^{-1} \mathrm{DW}$, respectively, which values were significantly greater than in the non-grafted $\mathrm{C}$ control plants (Figure 1A). On the $14^{\text {th }} \mathrm{d}$ (Figure 1B), there was no significant difference in the $\mathrm{B}$ concentration between grafted and non-grafted C plants. This is possibly due to greater growth rate of grafted plants this period and dilution effect of B concentration in leaves. All leaf B concentrations were lower than the toxic B level. The B concentration of CxA leaves is less than in the first week, probably due to a greater plant growth and B dilution effect. After $21 \mathrm{~d}$ (Figure 1C), there was a reduction in the $\mathrm{B}$ concentration of leaves in all grafted cvs in comparison to non-grafted $\mathrm{C}$ plants. On the other hand, our results show that pepper plants submitted to excessive B were capable of maintaining their growth for a certain period, despite $\mathrm{B}$ accumulation in leaves (Figure 1C). At $28 \mathrm{~d}$ (Figure 1D) the grafting treatments $\mathrm{CxT}, \mathrm{CxI}$ and $\mathrm{CxA}$ had significantly less B concentration in leaves compared to the ungrafted $C$ plants (Figure 1D). The concentrations of $\mathrm{B}$ in leaves in the ungrafted cvs $(\mathrm{T}, \mathrm{I}, \mathrm{A})$ were: 72-93 $\mu \mathrm{g} \mathrm{B} \mathrm{g}^{-1}$ at $7 \mathrm{~d}, 120-187 \mu \mathrm{g} \mathrm{B} \mathrm{g}^{-1}$ at $14 \mathrm{~d}$, and close to $200 \mu \mathrm{g} \mathrm{B} \mathrm{g}^{-1}$ at both 21 and $28 \mathrm{~d}$ (Figures $2 \mathrm{~A}$, $2 \mathrm{~B}, 2 \mathrm{C}, 2 \mathrm{D})$. These values were $82 \%$ greater compared to $\mathrm{B}$ concentration of leaves in grafted plants. If $\mathrm{B}$ concentration of leaves was expressed as a function of elapsed time (Figures 1E, 1F, 1G, 1H), a stepwise increase of leaf $\mathrm{B}$ concentration was recorded in the treatments of C-non-grafted, CxT and CxI (Figures $1 \mathrm{E}, 1 \mathrm{~F}, 1 \mathrm{G}$ ), while in $\mathrm{CxA}$ (Figure $1 \mathrm{H}$ ) a decrease was observed after 14 and $21 \mathrm{~d}$ followed by an increase at $28 \mathrm{~d}$.

When the B concentration of leaves was associated to elapsed time $(7,14,21,28 \mathrm{~d})$, the relationship was linear for non-grafted $\mathrm{C}$, grafted $\mathrm{CxT}$ and $\mathrm{CxI}$ plants with $\mathrm{r}^{2}$ values $0.83,0.94$ and 0.53 , respectively; while in CxA the relationship was expressed by a seconddegree equation with $\mathrm{r}^{2}=0.99$ (Table 1 ).

$\mathrm{B}$ concentration in leaves at $21 \mathrm{~d}$ and $28 \mathrm{~d}$ in nongrafted $\mathrm{C}$ plants was 114 and $145 \mu \mathrm{g} \mathrm{g} \mathrm{g}^{-1} \mathrm{DW}$, respectively (Figures 1C, 1D). The daily B accumulation in leaves was about $4 \mu \mathrm{g} \mathrm{g}^{-1} \mathrm{DW}$. In grafted cvs T, 
I, and $A$, there was an approximate $50 \%$ reduction in the $\mathrm{B}$ concentration in the leaves as compared to nongrafted $\mathrm{C}$ plants after 21 days of initiating the $\mathrm{B}$ stress application (Figure 1C) Moreover, $28 \mathrm{~d}$ after the initiation of the experiment, all the scion-cultivars had a significantly smaller B concentration compared to the non-grafted Century plants (Figure 1D).

Seven days after the initiation of the experiment, the $\mathrm{B}$ concentration in the roots of non-grafted plants was about $19 \mu \mathrm{g} \mathrm{g}^{-1} \mathrm{DW}$ (Figure 3A), while in the leaves it was close to $48 \mu \mathrm{g} \mathrm{g}^{-1} \mathrm{DW}$ (Figure 1A). A significant increase in $\mathrm{B}$ concentration in both the roots and leaves was recorded at 21 and $28 \mathrm{~d}$ after initiating the application of the solution containing B (Figures $1 \mathrm{C}, 1 \mathrm{D}$, Figures 3C, 3D). In the roots, there was a reduction of $\mathrm{B}$ concentration of $17 \%$ only in cultivar I (Figure $3 \mathrm{C}$ ) at $21 \mathrm{~d}$. There was no effect, however, on the $\mathrm{B}$ concentration of roots in cvs I or T at $28 \mathrm{~d}$. On the other hand, the combination $\mathrm{CxA}$ accumulated significantly more B in the roots than the non-grafted C plants (Figure 3D).

If the $\mathrm{B}$ concentration of roots is expressed as a function of elapsed time (Figures 3E, 3F, 3G, 3H), a stepwise increase of root $\mathrm{B}$ concentration was obvious in all treatments. When comparing grafted to nongrafted $\mathrm{C}$ plants, the greatest increase was recorded in the latter.

In the present experiment, the relationship between the $\mathrm{B}$ concentration of roots of grafted and nongrafted plants and the exposure time of B was linear with $\mathrm{r}^{2}$ values of $0.92,0.92,0.98$ and 0.96 for nongrafted $\mathrm{C}$ and grafted $\mathrm{CxT}, \mathrm{CxI}$ and $\mathrm{CxA}$, respectively (Table 1). The data indicate that $\mathrm{B}$ concentration of pepper plants was related to cv, grafting, exposure time to high B solution, as well as to plant organ, leaf or root. In general, the B concentration of leaves was two times greater than that of roots, indicating xylem transportation and transpiration driven accumulation of B in leaves.

\subsection{Total phenols and total flavonoids}

The concentration of total phenols and flavonoids was affected by grafting, scion-cultivar, and the duration of $\mathrm{B}$ stress treatment. Hence, $\mathrm{cv} \mathrm{T}$ as a scion contained more phenols $7 \mathrm{~d}$ after the initiation of the experiment, and its level was greater than in nongrafted $\mathrm{C}$ or grafted I and A plants (Figure 4A). After $14 \mathrm{~d}$ (Figure 5A), it appears that grafting reduced the concentration of phenol in the leaves in the CxT and $\mathrm{CxI}$ combinations as well as in all grafting combinations at $28 \mathrm{~d}$ (Figure 7A). No differences in phenol concentration were recorded between non-grafted and grafted $\mathrm{C}$ scion-cultivars $21 \mathrm{~d}$ after initiation of the $\mathrm{B}$ treatment (Figure 6A).

Regarding flavonoids, after $7 \mathrm{~d}$ of $\mathrm{B}$ stress, there was a 30\% increase in the $\mathrm{CxT}$ combination in comparison to non-grafted C plants (Figure 4B), whereas the flavonoid concentration in the other two scions was halved from $46 \%$ (I) to $23 \%$ (A). After $14 \mathrm{~d}$ of B treatment all the scion cvs showed a reduction in flavonoid concentrations by $43-50 \%$ of the non-grafted $C$ plants (Figure 5B). There was also a decrease recorded in flavonoids after $21 \mathrm{~d}$, for the cvs T, I and A, at 58\%, $77 \%$, and $67 \%$ of $\mathrm{C}$, respectively (Figure $6 \mathrm{~B}$ ). Likewise, the relative decrease in flavonoid concentrations at $28 \mathrm{~d}$ was significant and the obtained values were $51 \%, 35 \%$ and $82 \%$ of the non-grafted $\mathrm{C}$ for the cvs $\mathrm{T}$, I and A, respectively (Figure 7B).

\subsection{Total antioxidative capacity (FRAP)}

After $7 \mathrm{~d}$ of B treatment, the greatest antioxidant capacity of the leaves, as measured by the FRAP assay, was recorded in the combination CxI, which was $25 \%$ greater than the non-grafted C plants (Figure 4C). The combination CxT did not differ significantly from the non-grafted plants, whereas the CxA combination had a lower FRAP value $(60 \%)$ than non-grafted C plants. 
After $14 \mathrm{~d}$ of B treatment, the FRAP values for the C xT, CxI and CxA combinations were 67\%,51\% and $55 \%$ respectively of that in the non-grafted $\mathrm{C}$ plants (Figure 5C). Although at $21 \mathrm{~d}$ all the rootstock-scion combinations had $28 \%$ greater FRAP values than the non-grafted $\mathrm{C}$ plants (Figure 6C), at $28 \mathrm{~d}$ there was no significant difference for any of the rootstockscion combinations in comparison to the non-grafted C plants (Figure 7C). Overall, it appears that grafting increases the FRAP value when the period of the $\mathrm{B}$ treatment is extended to over $21 \mathrm{~d}$; on the contrary, grafting seems to reduce FRAP values when there are short periods of B stress.

\subsection{Antioxidative capacity DPPH (\% inhibition and mM ascorbic acid $g^{-1} \mathrm{FW}$ )}

Seven days after the initiation of B treatment, there was either a positive or negative effect on the DPPH value (\% inhibition) due to grafting. While the DPPH value increased by $30 \%$ in the CxT combination compared to the non-grafted C plants (Figure 4D), it decreased in the $\mathrm{CxI}$ and $\mathrm{CxA}$ combinations to $61 \%$ and $70 \%$, respectively.

At $14 \mathrm{~d}$ of B stress, grafting reduced the DPPH value. There was a significant decrease in the DPPH values of the CxT, CxI and CxA combinations by $63 \%$, $44 \%$ and $44 \%$ respectively in comparison to the nongrafted plants (Figure 5D).

After $21 \mathrm{~d}$ of $\mathrm{B}$ treatment, grafting increased the DPPH values for the scions T, I and A, by $28 \%, 28 \%$ and $23 \%$, respectively (Figure 6D). After $28 \mathrm{~d}$, there was an increase in the DPPH values for the $\mathrm{T}$ and I cvs by $20 \%$ and $10 \%$ respectively, whereas the CxA combination had a lower DPPH value (86\%) than that of the non-grafted $\mathrm{C}$ plants (Figure 7D).

When the antioxidant activity was expressed in $\mathrm{mM}$ Ascorbic acid g-1 FW (Figures 4E, 5E, 6E, 7E) the pattern was similar to the expression in $\%$ inhibition. The concentration of ascorbic acid $\left(\mathrm{mM} \mathrm{g}^{-1} \mathrm{FW}\right)$ after 7 and $14 \mathrm{~d}$ varied from 2-5 mMoles, while it increased to $10-12$ mMoles after 21 and $28 \mathrm{~d}$ of B treatment.

Table 1. Regression equations expressing the relationship between grafting treatments and time course of boron concentration in mature leaves and roots

\begin{tabular}{lcc}
\hline Treatment & Regression equation & $r^{2}$ \\
\hline Time course $(X)$ vs. boron concentration $(Y)$ in old leaves & \\
Century as ungrafted & $\mathrm{Y}=21.951 \mathrm{x}+29.037$ & 0.83 \\
Century grafted with Twingo & $\mathrm{Y}=19.318 \mathrm{x}+16.940$ & 0.94 \\
Century grafted with Imperial & $\mathrm{Y}=17.720 \mathrm{x}+30.494$ & 0.53 \\
Century grafted with Arlequin & $\mathrm{Y}=24.663 \mathrm{x}^{2}-118.3 \mathrm{x}+200.02$ & 0.99 \\
Time course $(X)$ vs. boron concetration $(\mathrm{Y})$ in roots & \\
Century as ungrafted & $\mathrm{Y}=9.6490 \mathrm{x}+9.430$ & 0.92 \\
Century grafted with Twingo & $\mathrm{Y}=8.4677 \mathrm{x}+14.458$ & 0.92 \\
Century grafted with Imperial & $\mathrm{Y}=7.1287 \mathrm{x}+15.742$ & 0.98 \\
Century grafted with Arlequin & $\mathrm{Y}=7.6803 \mathrm{x}+19.976$ & 0.96 \\
\hline
\end{tabular}




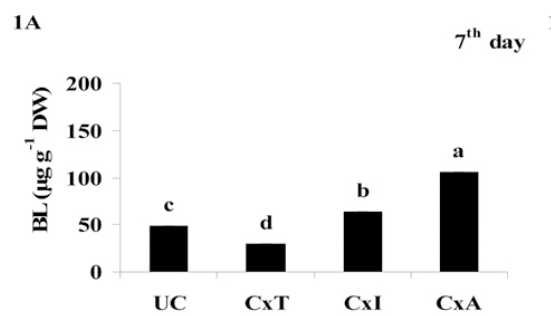

$14^{\text {th }}$ day

$1 \mathrm{C}$
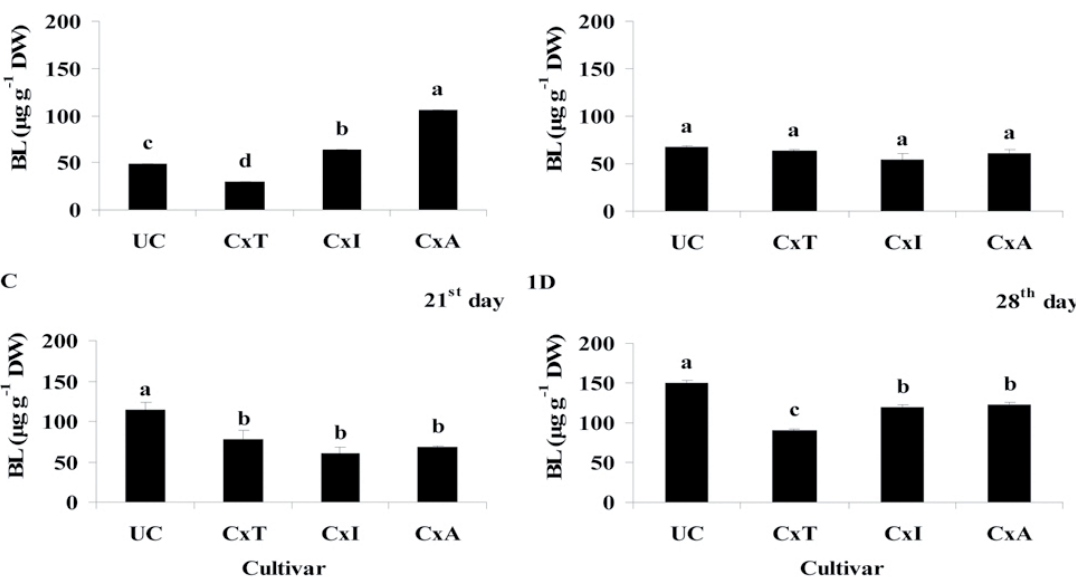

$1 E$

$1 \mathrm{~F}$
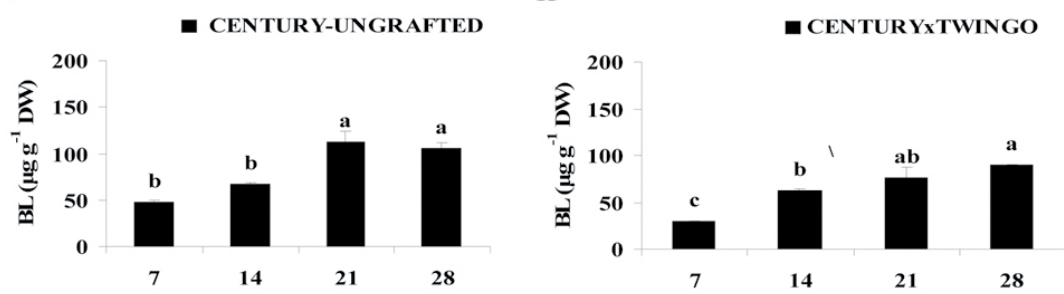

$1 G$

— CENTURYXIMPERIAL

$1 \mathrm{H}$
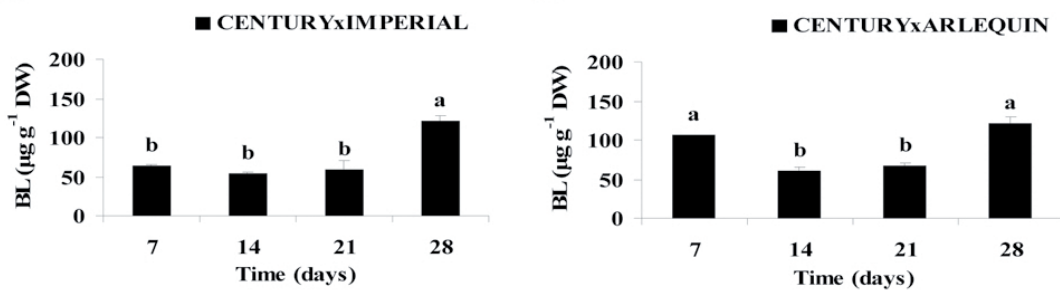

Figure 1. Figures 1A, 1B, 1C, 1D: The effects of grafting and pepper cultivar on the concentration of B in leaves at 7, 14, 21 and $28 \mathrm{~d}$ after the initiation of B treatment; Figures 1E, 1F, 1G, 1H: Time course of B accumulation in leaves in ungrafted $\mathrm{C}$ and grafted $\mathrm{C}$ combination cultivars as a function of time. Means followed by the same letter are not significantly different at $p \leq 0.05$ (Duncan's multiple range test, $\mathrm{n}=5$ ). BL: boron of leaves; DW: dry weight; B: boron; U: ungrafted; CxT: Century x Twingo; CxI: Century x Imperial; CxA: Century x Arlequin. 


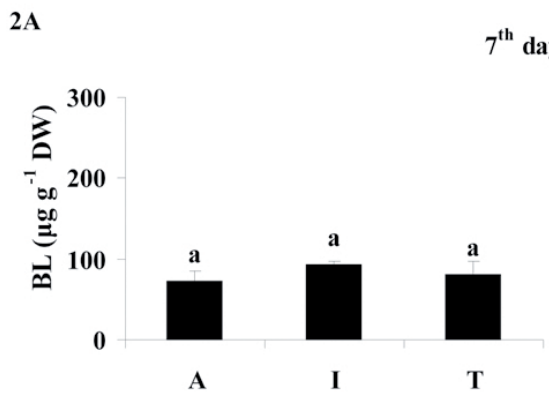

$2 B$

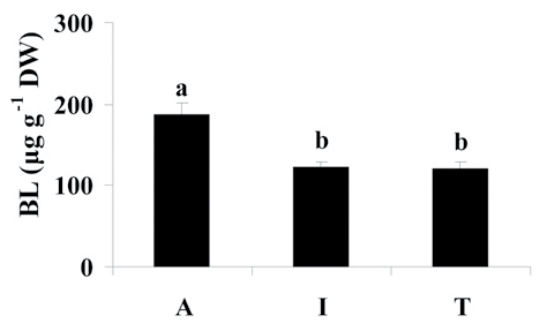

2C

$21^{\text {st }}$ day $2 \mathrm{D}$

$28^{\text {th }}$ day
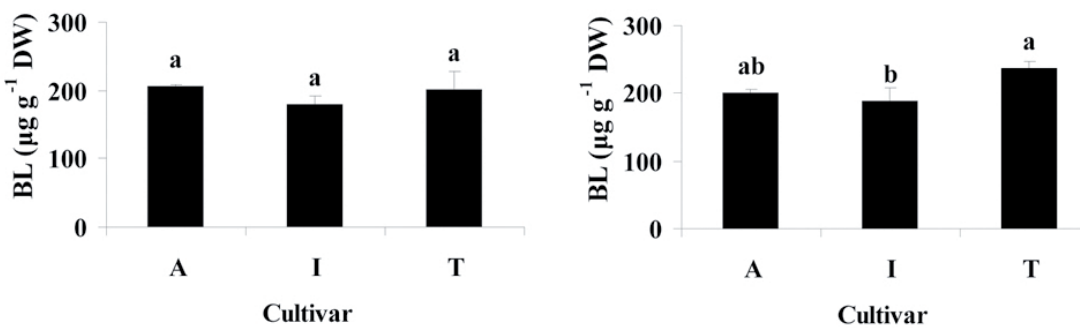

Figure 2. Figures 2A, 2B, 2C, 2D: Time course of B concentration 7, 14, 21 and 28 days in leaves of 3 pepper (Capsicum annuum L.) cultivars. Means followed by the same letter are not significantly different at $p \leq 0.05$ (Duncan's multiple range test, $n=5$ ). A: Arlequin; I: Imperial; T: Twingo. 

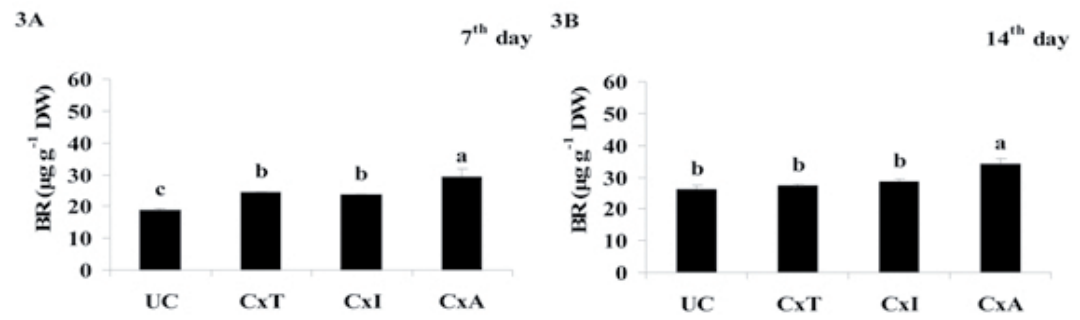

$3 \mathrm{C}$

$$
21^{\text {st }} \text { day } 3 \mathrm{D}
$$

$28^{\text {th }}$ day

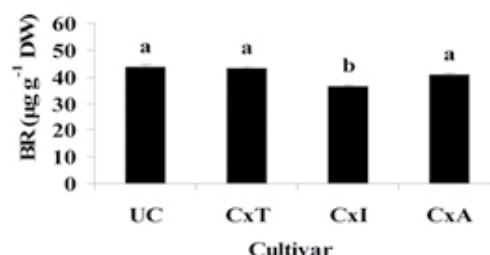

$3 E$

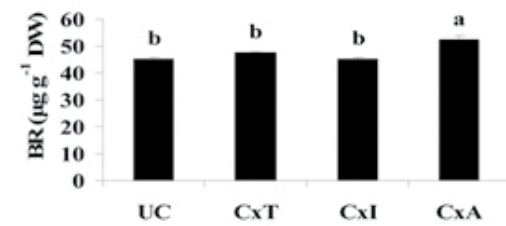

Cultivar

$3 \mathbf{F}$
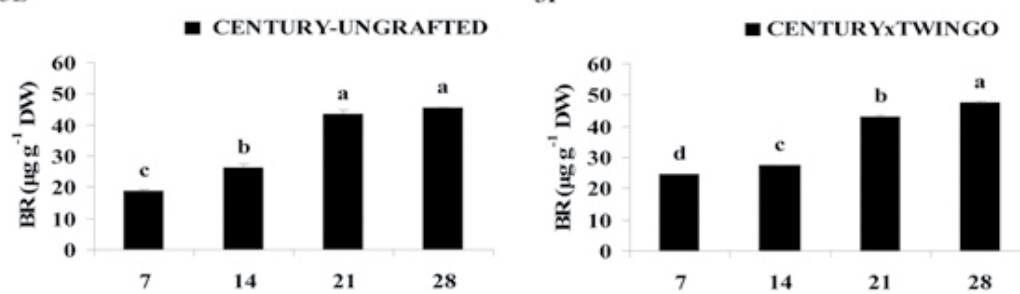

3G

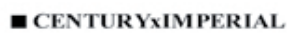

$3 \mathbf{H}$
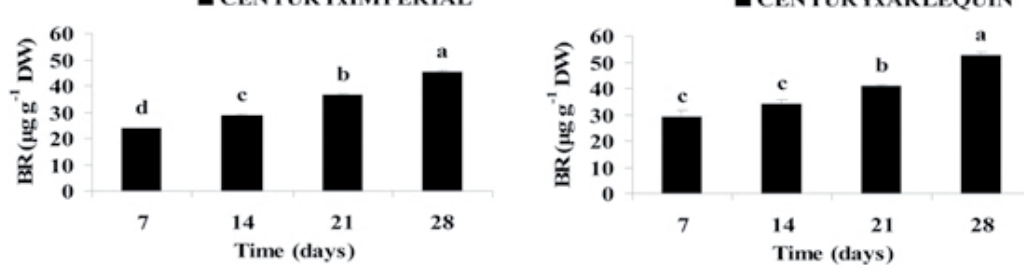

Figure 3. Figures 3A, 3B, 3C, 3D: The effects of grafting and pepper cultivar on the concentration of $\mathrm{B}$ in roots 7, 14, 21 and 28 days after the initiation of B treatment; Figures 3E, 3F, 3G, 3H: Time course of B accumulation in roots in each treatment as a function of time. Means followed by the same letter are not significantly different at $p \leq 0.05$ (Duncan's multiple range test, $\mathrm{n}=5$ ). BR: boron of roots; DW: dry weight; B: boron; U: ungrafted; CxT: Century x Twingo; CxI: Century x Imperial; CxA: Century x Arlequin. 


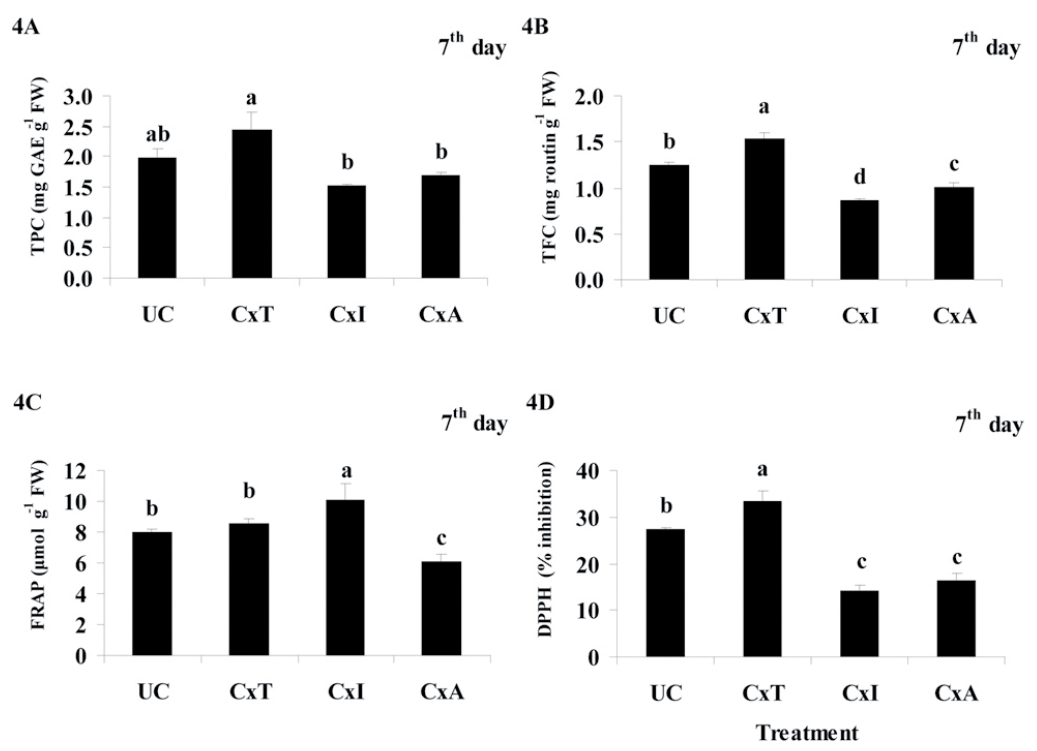

$4 \mathbf{E}$

$7^{\text {th }}$ day

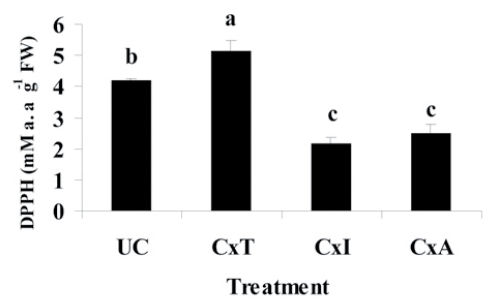

Figure 4. The effects of grafting and pepper cultivar on the concentration of phenols (Figure 4A), flavonoids (Figure 4B), and the antioxidant capacity in leaves (Ferric reducing antioxidant potential (FRAP) (Figure 4C), and 2,2-diphenyl-1-picryl hydrazyl (DPPH) (Figures 4D, 4E)), 7 days after the initiation of B treatment. Means followed by the same letter are not significantly different at $p \leq 0.05$ (Duncan's multiple range test, $\mathrm{n}=5$ ). TPC: total phenol concentration; TFC: total flavonoid concentration B: boron; FW: fresh weight; a.a: ascorbic acid; U: ungrafted; CxT: Century x Twingo; CxI: Century x Imperial; CxA: Century x Arlequin. 


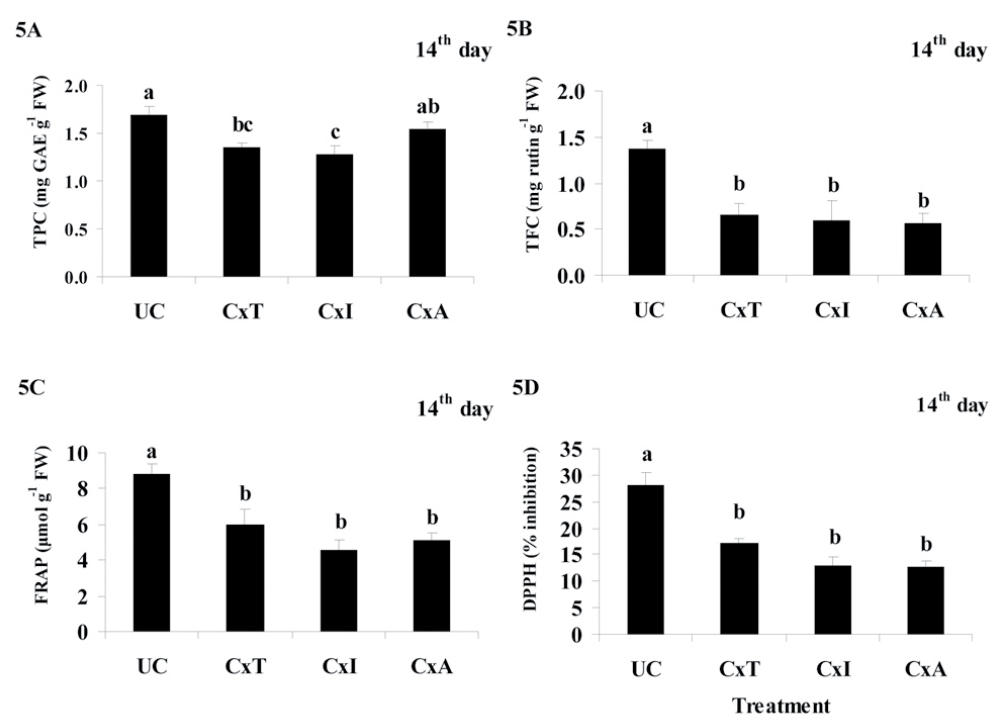

$5 \mathbf{E}$

$$
14^{\text {th }} \text { day }
$$

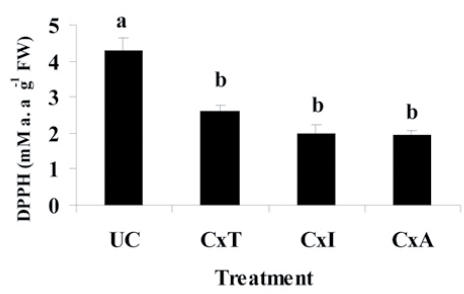

Figure 5. The effects of grafting and pepper cultivar on the concentration of phenols (Figure 5A), flavonoids (Figure 5B), and the antioxidant capacity in leaves (Ferric reducing antioxidant potential (FRAP) (Figure 5C) and 2,2-diphenyl-1-picryl hydrazyl (DPPH) (Figures 5D, 5E)), 14 days after the initiation of boron treatment. Means followed by the same letter are not significantly different at $\mathrm{p} \leq 0.05$ (Duncan's multiple range test, $\mathrm{n}=5$ ). TPC: total phenol concentration; TFC: total flavonoid concentration B: boron; FW: fresh weight; a.a: ascorbic acid; U: ungrafted; CxT: Century x Twingo; CxI: Century x Imperial; CxA: Century x Arlequin. 

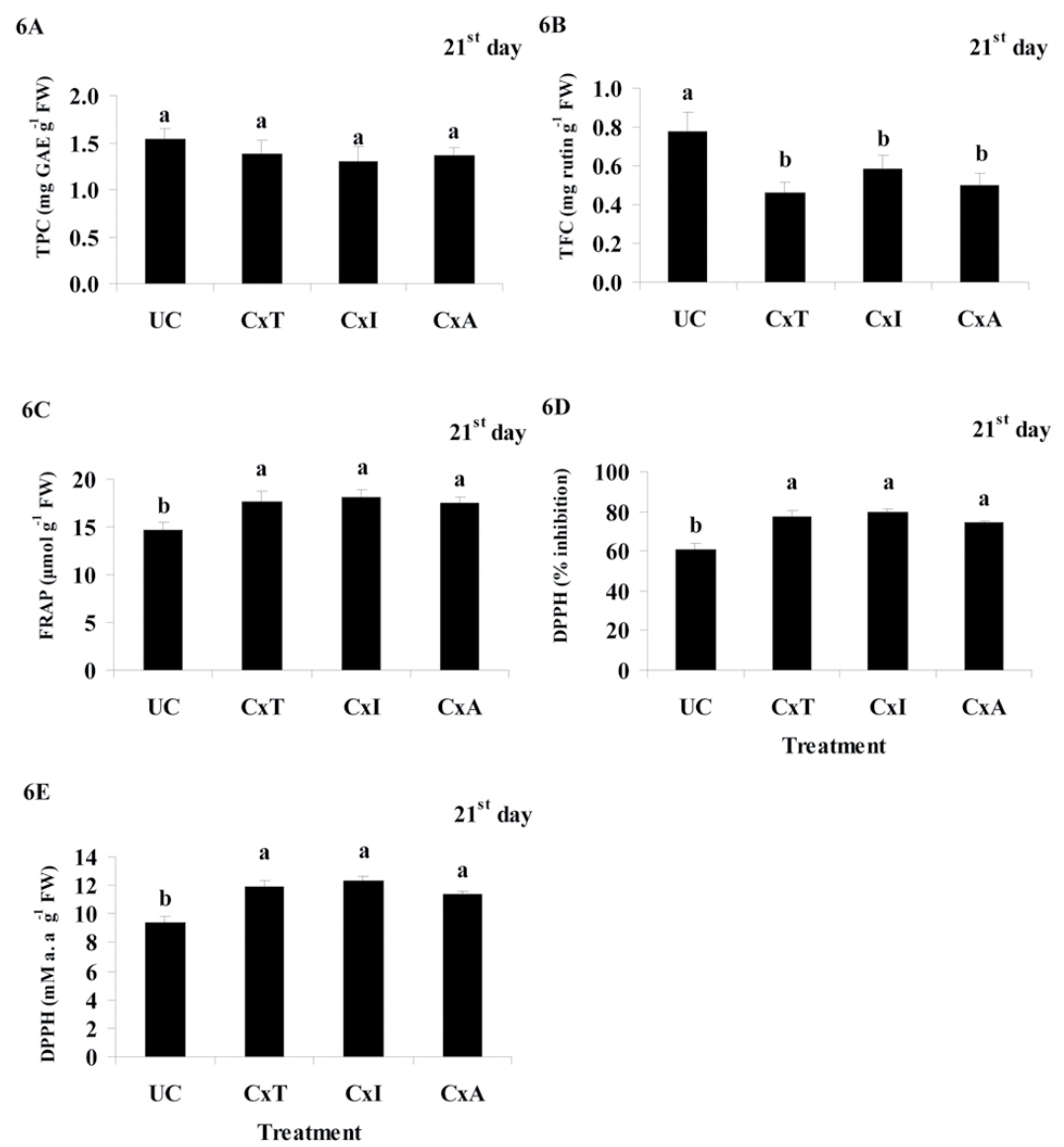

Figure 6. The effects of grafting and pepper cultivar on the concentration of phenols (Sub-figure 6A), flavonoids (Figure 6B), and the antioxidant capacity in leaves (Ferric reducing antioxidant potential (FRAP) (Figure 6C) and 2,2-diphenyl-1-picryl hydrazyl (DPPH) (Figures 6D, 6E)), 21 days after the initiation of boron treatment. Means followed by the same letter are not significantly different at $p \leq 0.05$ (Duncan's multiple range test, $\mathrm{n}=5$ ). TPC: total phenol concentration; TFC: total flavonoid concentration B: boron; FW: fresh weight; a.a: ascorbic acid; U: ungrafted; CxT: Century x Twingo; CxI: Century x Imperial; CxA: Century x Arlequin. 


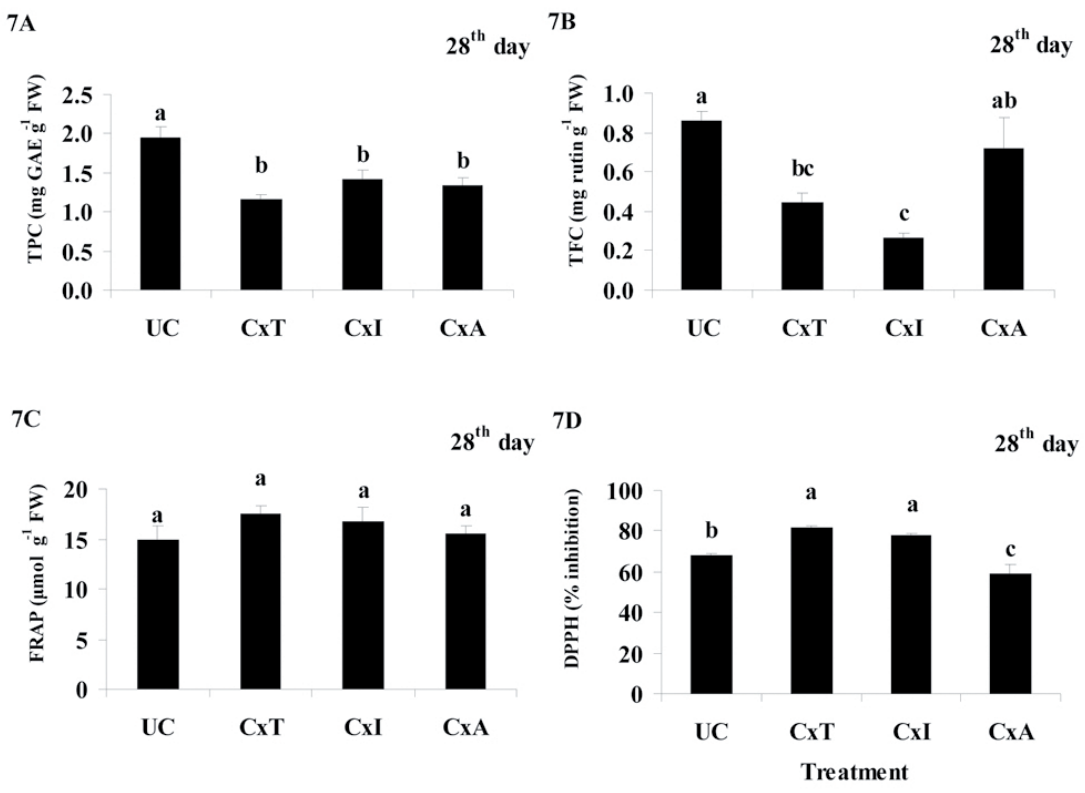

7 E

$28^{\text {th }}$ day

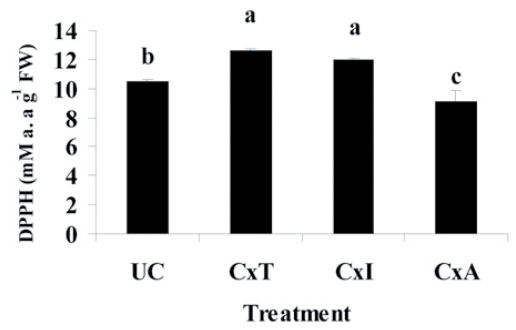

Figure 7. The effects of grafting and pepper cultivar on the concentration of phenols (Figure 7A), flavonoids (Figure 7B), and the antioxidant capacity in leaves (Ferric reducing antioxidant potential (FRAP) (Figure 7-C) and 2,2-diphenyl-1-picryl hydrazyl (DPPH) (Figures 7D, 7E)), 28 days after the initiation of boron treatment. Means followed by the same letter are not significantly different at $p \leq 0.05$ (Duncan's multiple range test, $\mathrm{n}=5$ ). TPC: total phenol concentration; TFC: total flavonoid concentration B: boron; FW: fresh weight; a.a: ascorbic acid; U: ungrafted; CxT: Century x Twingo; CxI: Century x Imperial; CxA: Century x Arlequin 


\section{Discussion}

In the present study, the effects of $5 \mathrm{mg} \mathrm{B} \mathrm{L}^{-1}$ concentration in the nutrient solution on grafted and non-grafted pepper plants were evaluated. For commercial cultivation, typically low concentrations of $B\left(0.2 \mathrm{mg} \mathrm{L}^{-1}\right)$ are used in solutions, which have been found adequate for plant growth. However, at this level of B concentration, we found no difference in the B concentration of leaves between the grafted and non-grafted plants (data not presented). B toxicity symptoms appeared in the non-grafted plants (slight chlorosis of leaf margins) on the old leaves with $5 \mathrm{mg}$ $\mathrm{B} \mathrm{L}^{-1}$ in the nutrient solution, which is in agreement with Sarafi et al. (2017). In addition, with $5 \mathrm{mg} \mathrm{B} \mathrm{L}^{-1}$, there was an increase in the $\mathrm{B}$ acquisition by the roots from the perlite substrate. In the aerial sections of the plant, however, the process of B distribution is still poorly understood. It is assumed that B build-up in the plant's leaves is caused by the accumulation of B that is transported via the transpiration stream (Chatzissavvidis and Therios, 2011). It has been found that B tends to accumulate in old leaves because an insignificant amount is retranslocated from the original sites. In the grafted pepper plants on $\mathrm{C}$ of the cvs $\mathrm{T}$, I, and A of the present study, only slight symptoms of B toxicity were observed later in the growing season, in comparison to non-grafted peppers, which exhibited severe B toxicity. Goldberg et al. (2003) reported a similar effect of B on leaf chlorosis in non-grafted melons. These symptoms in the plant's leaves might be caused by B accumulation, resulting in the plants becoming physiologically damaged (Bingham, 1982). On the whole, the old leaves of the plant are expected to have the highest concentration of $\mathrm{B}$ as it is here that $\mathrm{B}$ has transpired for the longest time, having been transported passively through the water flow. This relationship indicates that the $\mathrm{B}$ concentration in mature leaves could be used as a better indicator of $\mathrm{B}$ concentration in the entire plant. The relationship between B accumulation and exposure time to B stress was linear in non-grafted plants and in two rootstock-scion combinations (Table 1). Goldberg et al. (2003) found that as B concentration in the soil solution increased, the B concentration in the leaves of non-grafted melon cv Top Mark also increased linearly. Our results indicated that at 21 and $28 \mathrm{~d}$ of culture, the grafted $\mathrm{C}$ plants had accumulated less $\mathrm{B}$ than the non-grafted $\mathrm{C}$ plants, when exposed to $5 \mathrm{mg} \mathrm{L}^{-1} \mathrm{~B}$ concentration, meaning they were less sensitive to B toxicity. The findings thus, showed that grafted pepper plants absorbed less B, transported less $\mathrm{B}$ to the leaves and could also be less sensitive to $\mathrm{B}$ accumulation than their non-grafted counterparts. Edelstein et al. (2005) reached a similar conclusion for melon plants irrigated with fresh or saline water.

The B concentration of pepper leaves could be affected by the following factors: (a) The concentration of $\mathrm{B}$ in the nutrient or soil solution around the roots (in our study, however, the pepper plants were grown in perlite filled pots, an inert medium, and were irrigated to excess, therefore, $\mathrm{B}$ concentration in the nutrient solution was similar to the B level around the roots); (b) The transpiration rate, which is related to total leaf dry biomass in pepper plants (Letey and Dinar, 1986); (c) High membrane permeability and easily leaching by rain; and (d) Capacity for efflux pumping of $\mathrm{B}$ from root into the external medium (Chatzissavvidis and Therios, 2011). Our results suggest that the B concentration in the leaves of the grafted plants at 21 and $28 \mathrm{~d}$ of culture was lower than those in the nongrafted cvs C, T, A and I (Figure 2), since the former plants excluded more B than the latter. The greater B exclusion was probably achieved by the rootstock or grafting union. B uptake was reduced at high B concentration, either by excretion or B exclusion or by its efflux (Hayes and Reid, 2004). It is likely that, one of these mechanisms is also at work in pepper plants but further research is necessary to determine this point. 
The influence of the rootstock cvs on the mineral concentration of aerial plant parts was attributed to physical characteristics of the root systems, such as lateral and vertical root extension, which resulted in enhanced or reduced uptake of minerals. Vertical root extension is one of the many motives for the widespread use of grafted rootstocks (Lee, 1994). In water melon plants, it was found that lower accumulation of B in leaves was obtained when they were grafted onto squash, indicating the ability of the rootstocks to exclude B and possibly limit its transport to the leaves (Edelstein et al., 2005). Similar results were found in tomato plants for $\mathrm{Cu}, \mathrm{Fe}$ and $\mathrm{Mg}$ with lower translocation of these elements to the leaves of the plants grafted onto 'He-Man' in comparison to the self-grafted plants (Savvas et al., 2009).

The decreased B concentration observed in grafted plants at 21 and $28 \mathrm{~d}$ may be explained by the smaller root system, weight and restricted hydraulic conductivity from the rootstock to the scion. The fact that at $14 \mathrm{~d}$ of culture, no difference in B concentration of the leaves between grafted and non-grafted plants was recorded probably indicates that this duration was not adequate for the expression of the effects of B toxicity or a decrease in B absorption. Furthermore, both the rootstock and the scion affect stomatal performance, leading to a higher carbon dioxide $\left(\mathrm{CO}_{2}\right)$ assimilation rate and less stomatal resistance than in non-grafted plants (He et al., 2009). Significant differences were recorded at 21 and $28 \mathrm{~d}$ between the three scion-cvs concerning the B concentration of leaves in comparison to non-grafted plants in C. Boron uptake and its modification is regulated by complex communication mechanisms between the scion and the rootstock. Root to shoot, as well as top to root graft transmissible signals have been demonstrated (Molnar et al., 2010). The final leaf $B$ concentration is affected by transport recirculation and uptake, as well as scion growth (Nawaz et al., 2016).
Many rootstocks used for grafting vegetables are able to increase the uptake rates of some nutrients because they constitute a more vigorous root system than those of elite varieties (Savvas et al., 2013). The C $\mathrm{cv}$ used as rootstock in the present study reduced B uptake and translocation to the shoots and leaves of pepper cvs that were used as scions. This is in agreement with other authors who worked on a variety of nutrients. For instance, Edelstein and Ben-Hur (2007) reported that the concentration of $\mathrm{Mn}$ in melon plants grafted onto TZ-148 was substantially lower than that measured in non-grafted plants. This response indicates that the translocation of B from the root to the shoot is impaired by the grafting incision.

Mechanisms which are considered to regulate nutritional and developmental relations between the roots and shoots include long distance protein, mRNA and small RNA graft transmissible signals, which might be important for grafting physiology (Goldschmidt, 2014). In addition, miRNAs play a vital role in the maintenance of nutrient homeostasis in plants, and thus, regulate the expression of the transporters who mobilize nutrients to the leaves (Paul et al., 2015). Another factor which can reduce B transport to the leaves of grafted plants are the differences in sugar formation and miRNAs between cvs, which function as long-distance signalling molecules and regulate both B uptake and transport (Nawaz et al., 2016). Decreased sugar formation in grafted plants reduces the energy pool available for the uptake and transportation of $\mathrm{B}$, due to the effects of grafting on the photosynthetic metabolism (Amaro et al., 2014) as well as the hormonal levels (cytokinin and auxin) (Albacete et al., 2009). The data from the present study cannot specify which of the above-mentioned mechanisms are involved in B mobilization to the leaves. However, our findings suggest that grafted pepper plants can have the effect of limiting the absorption and transportation of $\mathrm{B}$ from the roots to the 
leaves. This is most likely due to the grafting zone differences in miRNAs, which function as long distance signaling molecules, also the hormonal levels (cytokinin and auxin), as well as differences in the sugar formation of the various rootstock-scion combinations. Thus, further research is necessary in order for this point to be better determined.

Although the rootstock genotype determines the uptake rate of $\mathrm{B}$, the response of the grafted plant to excessive $\mathrm{B}$ is determined ultimately by the scion cv. When a rootstock that is excess B tolerant is grafted onto a particular scion genotype, might prove to be completely inefficient in enhancing B stress tolerance. Our results emphasize the need to test each grafting combination and not merely each rootstock for its ability to ameliorate B toxicity.

Another metabolic process that has been associated with the resistance responses to different types of abiotic stresses in plants involves phenolic compounds. Phenols help to prevent the formation of reactive oxygen species (ROS). Secondly, phenolic compounds also display antioxidant action which depends primarily on the number and position of hydroxyl groups in the structure (Cai et al., 2006). The concentration of total phenols and flavonoids is affected by grafting and scion cvs. In general, grafting with two of three tested cvs reduced the phenol concentration of leaves at 7, 14 and $28 \mathrm{~d}$ compared to non-grafted plants. The mechanism of this decrease is not clear, however, the grafting zone hindering the transportation of metabolites and minerals cannot be excluded. Similarly, the level of flavonoids was reduced by grafting. Likewise, it is possible that the mechanism involved is the grafting zone hindering the transportation of certain metabolites from the roots to the leaves, which are required for flavonoid synthesis.

The FRAP values showed that antioxidant capacity rose as the duration of the $\mathrm{B}$ treatment increased, culminating in the highest value at $28 \mathrm{~d}$. This indicates that high B promoted the production of ROS. Furthermore, grafting increased the antioxidative capacity. There are only a few studies available on the antioxidant responses of plants associated to toxic levels of B. Hence, our data agree with Ardic et al. (2009) who reported increases in the antioxidant capacity and phenolic metabolism in plants suffering from B toxicity. However, some researchers (Keles et al., 2004) found no significant changes in the phenol concentration when the irrigation water contained high $\mathrm{B}$. The DPPH value was a function of $\mathrm{cv}$. Therefore, the $\mathrm{cv} \mathrm{T}$ increased the DPPH value to $30 \%$ in the CxT combination and decreased it in the combinations $\mathrm{CxI}$ and CxA. The mechanism responsible for this difference in behavior could be ascribed to the scion but further research is required to explain this on the basis of plant physiology and molecular biology.

\section{Conclusions}

The present study shows that high B concentration in the growth substrate provokes oxidative damage in leaves, inducing a general response of antioxidant mechanisms. The grafted plants probably could exclude some B and this in turn reduced its concentration in the leaves. This was most likely achieved by the rootstock, scion cvs, or the grafting zone. Another important outcome is that the $\mathrm{C} \mathrm{cv}$ could be used in agricultural practice as a rootstock for reducing $\mathrm{B}$ toxicity problems in the cvs T, I and A, which is an innovation in the area of vegetable crops.

\section{Acknowledgements}

We would like to express our sincere gratitude to Agris Nurseries for kindly providing the ungrafted pepper plants; also, our sincere thanks to S. Kouti and V. Tsakiridou for technical assistance in the preparation of the grafted plants. The authors gratefully acknowledge 
the financial support of the Aristotle University of Thessaloniki.

\section{References}

Albacete, A., Martinez-Andújar, C., Ghanem, M.E., Acosta, M., Sánchez-Bravo, J., Asins, M. J., Cuartero, J., Lutts, S., Dodd, I.C., Pérez-Alfocea, F. 2009. Rootstock-mediated changes in xylem ionic and hormonal status are correlated with delayed leaf senescence, and increased leaf area and crop productivity in salinized tomato. Plant Cell Environ. 32, 928-938.

Akinci, I.E. 2006. Effect of boron toxicity on yield and plant characteristics in red pepper (Capsicum annuит L.). Conference paper Sept. 2006. https:// www.researchgate.net/publication/306119180.

Amaro, A.C.E., Macedo, A.C., Ramos, A.R.P., Goto, R., Ono, E.O., Rodrigues, J.D. 2014. The use of grafting to improve the net photosynthesis of cucumber. Theor. Exp. Plant Physiol. 26, 241-249.

Ardic, M., Sekmen, A.H., Turkan, I., Tokur, S., Ozdemir, F. 2009. The effects of boron toxicity on root antioxidant systems of two chickpea (Cicer arietinum L.) cultivars. Plant Soil. 314, 99-108.

Bingham, F.T. 1982. Boron. In: Methods of Soil Analysis Part II. Chemical and Microbiological Properties (ed). A.L. Page. American Society of Agronomy, Madison, WI, USA, pp: 431-449.

Cai, Y.Z., Sun M., Xing, J., Luo, Q., Corke, H. 2006. Structure-radical scavenging activity relationships of phenolic compounds from traditional Chinese medicinal plants. Life Sciences. 78, 2872-2888.

Cervilla, L.M., Blasco, B., Rios, J.J, Romero, L., Ruiz, J.M. 2007. Oxidative stress and antioxidants in tomato (Solanum lycopersicum) plants subjected to boron toxicity. Ann. Bot. 100, 747-756.
Chatzissavvidis, C., Therios, I., Antonopoulou, C., Dimassi, K. 2008. Effects of high boron concentration and scion-rootstock combination on growth and nutritional status of olive plants. J. Plant Nutr. 31, 638-658.

Chatzissavvidis, C. and Therios, I. 2011. Boron in higher plants. In. Perkins GL (ed.). Boron: Compounds, production and application. Nova Science Publishers Inc. pp.147-176.

Edelstein, M., Ben-Hur, M., Cohen, R., Burger, Y., Ravina, I. 2005. Boron and salinity effects on grafted and non-grafted melon plants. Plant Soil. 267, 273-284.

Edelstein, M., Ben-Hur, M. 2007. Preventing contamination of supply chains by using grafted plants under irrigation with marginal water. In. Wilson J (ed). Proceedings of the international symposium on water resources management. Honolulu, Hawaii, USA pp: 150-154.

Edelstein, M., Plaut, Z., Ben-Hur, M. 2011. Sodium and chloride exclusion and retention by nongrafted and grafted melon and Cucurbita plants. J. Exp. Bot. 62, 177-184.

El-Motaium, R., Hu, H., Brown, P.H. 1994. The relative tolerance of six Prunus rootstocks to boron and salinity. J. Am. Soc. Hort. Sci. 119, 11691175.

Estan, M.T., Martinez-Rodriguez, M., Perez-Alfocea, F., Flowers, T.J., Bolarin, M.C. 2005. Grafting raises the salt tolerance of tomato through limiting the transport of sodium and chloride to the shoot. J. Exp. Bot. 56, 703-712.

Goldberg, S., Shouse, P.J., Lesch, S.M., Grieve, C.M., Poss, J.A., Foster, H.S, Suarez, D.L. 2003. Effect of high boron application on boron content and growth of melons. Plant Soil. 256, 403-411.

Goldschmidt, E.E. 2014. Plant grafting: new mechanisms, evolutionary implications. Front. Plant Sci. 5, 727. doi.org/10.3389/fpls.2014.00727 
Hasler, C.M. 1998. Functional foods: their role in disease prevention and health promotion. Food Technol. 52, 63-69.

Hayes, J.E., Reid, R.J. 2004. Boron tolerance in barley is mediated by efflux of boron from the roots. Plant Physiol. 136, 376-3382.

He, Y., Zhu, Z., Yang, J., Ni, X., Zhu, B. 2009. Grafting increases the salt tolerance of tomato by improvement of photosynthesis and enhancement of antioxidant enzymes activity. Env. Exp. Bot. 66, 270-278.

Keles, Y., Öncel, I., Yenice, N. 2004. Relationship between boron content and antioxidant compounds in Citrus leaves taken from fields with different water source. Plant Soil. 265, 345-353.

Lee, J.M. 1994. Cultivation of grafted vegetables. I. Current status, grafting methods and benefits. HortScience. 23, 235-239.

Letey, J., Dinar, A. 1986. Simulated crop-water production functions for several crops when irrigated with saline waters. Hilgardia. 54, 1-32.

Mastrogiannidou, E., Chatzissavvidis, C., Antonopoulou, C., Tsabardoukas, V., Giannakoula, A., Therios, I. 2016. Response of pomegranate cv. wonderful plants to salinity. J. Soil Sci. Plant Nutr. 16, 621-636.

Meriño-Gergichevich, C., Ondrasek, G., Zovko, M., Šamec, D., Alberdi, M., Reyes-Díaz, M. 2015. Comparative study of methodologies to determine the antioxidant capacity of Al-toxified blueberry amended with calcium sulfate. J. Soil Sci. Plant Nutr. 15, 965-978.

Molnar, A., Melnyk, C.W., Bassett, A., Hardcastle, T.J., Dunn, R., Baulcombe, D.C. 2010. Small silencing RNAs in plants are mobile and direct epigenetic modification in recipient cells. Science $328,872-875$.

Nawaz, M.A., Imtiaz, M., Kong, Q., Cheng, F., Ahmed, W., Huang, Y., Bie, Z. 2016. Grafting:
A technique to modify ion accumulation in horticultural crops. Front. Plant Sci. 7, 1457. doi: 10.3389/fpls.2016.01457

Paparnakis, A., Chatzissavvidis, C., Antoniadis, V. 2013. How apple responds to boron excess in acidic and limed soil. J. Soil. Sci. Plant Nutr. 7, 787-796.

Paul, S., Datta, S. K., Datta, K. 2015. miRNA regulation of nutrient homeostasis in plants. Front. Plant Sci. 6, 232. doi: 10.3389/fpls.2015.00232

Rafique, E., Mahmood-ul-Hassan, M., Khokhar, K.M., Ishaq, M., Yoursa, M., Tabassam, T. 2012. Boron requirement of chili (Capsicum annuum L.): Proposed diagnostic criteria, J. Plant Nutr. $35,739-740$.

Reid, R.J., Hayes, J.E., Post, A., Stangoulis, J.C.R., Graham, R.D. 2004. A critical analysis of the causes of boron toxicity in plants. Plant Cell Environ. 25, 1405-1414.

Sarafi, E., Chatzissavvidis, C., Therios, I. 2016. Response of two pomegranate (Punica granatum L.) cultivars to five B concentrations: Growth performance, B, chlorophyll and proline concentration. J. Plant Nutr. 40, 983-994.

Sarafi, E., Tsouvaltzis, P., Chatzissavvidis, C., Siomos, A., Therios, I. 2017. Melatonin and resveratrol reverse the toxic effect of high boron (B) and modulate biochemical parameters in pepper plants (Capsicum annuum L.). Plant Physiol. Bioch. 112, 173-183.

Savvas, D., Papastavrou, D., Ntatsi, G., Robokis, A., Olympios, C., Hartmann, H., Schwarz, D. 2009. Interactive effects of grafting and manganese supply on growth, yield and nutrient uptake by tomato. Hort.Science. 44, 1978-1982.

Savvas, D., Ntatsi, G., Barouchas, P. 2013. Impact of grafting and rootstock genotype on cation uptake by cucumber (Cucumis sativus $\mathrm{L}$.) exposed to $\mathrm{Cd}$ or Ni stress. Sci. Hortic. 149, 86-96. 
Schwarz, D., Rouphael, Y., Colla, G., Venema, J. H. 2010. Grafting as a tool to improve tolerance of vegetables to abiotic stresses. Thermal stress, water stress and organic pollutants. Sci. Hortic. 127, 162-171.
Tanwar, A., Aggarwal, A., Kadian, N., Gupta, A. 2013. Arbuscular mycorhizal inoculation and super phosphate application influence plant growth and yield of Capsicum annuum. J. Soil Sci. Plant Nutr. 13, 55-66. 